\title{
Synthesis
}

International Scientific Conference of IT and Business-Related Research

\section{NEMATERIJALNO KULTURNO NASLEĐE: TURISTIČKI RESURS SRBIJE}

\author{
INTANGIBLE CULTURAL HERITAGE: TOURISM RESOURCE OF SERBIA
}

\author{
Branko Krasojević ${ }^{1}$, Biljana Đorđević ${ }^{2}$ \\ ${ }^{1}$ Agencija „Savetnik u turizmu“, Bože Baucala 20/3 Beograd, Srbija \\ ${ }^{2}$ Narodni muzej, Trg Republike 1a, Beograd, Srbija
}

\begin{abstract}
Apstrakt:
Nematerijalno kulturno nasleđe kao faktor promovisanja i razvoja kulturnog i nacionalnog identiteta u fokusu je pažnje UNESKO-a, Svetske turističke organizacije (UNWTO) i drugih međunarodnih organizacija za kulturu i turizam, čime se značajno generiše turistička tražnja. U turističkoj ponudi Srbije nematerijalno kulturno nasleđe je skromno zastupljeno, često neadekvatno prezentovano i interpretirano. Projekat „Podrška sprovođenju Nacionalne strategije razvoja turizma" potvrdio je da veliki kulturni potencijali Srbije mogu doprineti socio-ekonomskom razvoju, generisanju prihoda, jačanju deviznih rezervi i otvaranju novih radnih mesta. Cilj ovog rada je da ukaže na značaj nematerijalnog nasleđa kao faktora generisanja kritične mase savremeno interpretiranih kulturno-turističkih proizvoda, koji mogu da unaprede konkurentnost turističke ponude Srbije.
\end{abstract}

\section{Ključne reči:}

kulturni turizam, turistički proizvod, konkurentnost, UNESCO.

\section{UVOD}

Nematerijalno kulturno nasleđe je dostiglo svoju afirmaciju usvajanjem Konvencije o kulturnom nasleđu 2003. godine. (UNESCO, 2003). Konvencijom je definisano kulturno nasleđe i po prvi put su date preporuke za očuvanje, zaštitu i revitalizaciju ove specifične kategorije. To znači da se nematerijalno kulturno nasleđe prema Konvenciji o očuvanju nematerijalnog kulturnog nasleđa (Član 2, Stav 1. i 2.) prepoznaje u oblastima kao što su: usmena tradicija, izvođačke umetnosti, običaji i rituali, znanja i veštine starih zanata i domaće radinosti. Promovisanje nematerijalnog kulturnog nasleđa na osnovu ove Konvencije sprovodi se kroz tri liste na kojima se prezentuju reprezentativno nasleđe čovečanstva, nasleđe kome je potrebna hitna zaštita i dobre prakse (Đorđević, 2012, str. 14-18).

Osnovni cilj Konvencije o očuvanju nematerijalnog kulturnog nasleđa je njegova zaštita i revitalizacija. Pri tome, pod terminom revitalizacije ne podrazumevamo ponovno oživljavanje ugašenih i zaboravljenih običaja, znanja i veština, već podsticaj onima koji uprkos negativnim uticajima globalizacije ne napuštaju negovanje lokalne tradicije koja ih identifijuje kao zajednicu ili grupu, nastojeći, da prenošenjem na mlađe generacije obezbede kontinuitet identiteta koji ih definiše. S toga su podizanje svesti lokalnih zajednica i grupa koje neguju određene elemente nematerijalnog kulturnog nasleđa i njihova edukacija od suštinskog značaja (Đorđević, 2012, str. 60). Najbolji način sprovođenja ovakve strategije je ukazivanje na značaj nematerijalnog kulturnog nasleđa za širu lokalnu i globalnu zajednicu kroz koncept integrativne zaštite (Popović-Živančević, 2012).

\section{Abstract:}

Intangible cultural heritage, as a factor of promotion and development of the cultural and national identity, attracts considerable attention of the UNESCO, UNWTO and other international cultural and tourism organizations, thereby significantly generating tourism demand. Intangible cultural heritage is modestly represented in the tourism supply of Serbia, and is often inadequately promoted and interpreted. The project "Support to implementation of the National Strategy for Tourism" confirmed that the great cultural resources of Serbia can contribute to socioeconomic development, income generation, strengthening of foreign exchange reserves and creation of new jobs openings. The aim of this paper is to highlight the importance of intangible heritage as a factor generating the critical mass of modern interpreted cultural-tourism products, which can significantly enhance the competitiveness of Serbia's tourism supply.

\section{Key words:}

cultural tourism, tourism product, competitiveness, UNESCO

Kulturni turizam može značajno da doprinese sprovođenju pomenute strategije, jer omogućava lokalnim zajednicama ne samo da prepoznaju širi značaj svoje tradicije, već i da je učine održivom, što olakšava njenu prezervaciju i prenošenje na sledeće generacije. Srbija bi mogla svoje bogato, a turistički nevalorizovano nematerijalno nasleđe, da uvrsti u turističku ponudu i tako poveća svoju izuzetno nisku tržišnu konkurentnost.

\section{KULTURA I TURIZAM}

Kultura i turizam se poslednjih godina sve čvršće povezuju. Interesovanje za kulturu i kulturne programe, a među njima i one čija je okosnica nematerijalno kulturno nasleđe, u neprestanom je porastu. Svetska turistička organizacija navodi da je broj turista u kulturnom turizmu porastao sa $37 \%$ u 1995. na $40 \%$ u 2004. godini. Organizacija za ekonomsku saradnju i razvoj (OECD) u izveštaju iz 2009. godine, potvrđuje da kulturni turizam u 2007. godini predstavlja motiv za skoro 360 miliona međunarodnih turističkih putovanja, što čini oko $40 \%$ celokupnog svetskog turizma.

Turisti se sve više interesuju za različite kulture, izvođačke umetnosti, zanate, rituale, gastronomiju i tumačenja prirode i univerzuma. Svetski dan turizma 2011. godine, u svetu proslavljen je pod geslom „Turizam: povezivanje kultura” (Study on Tourism and Intangible Cultural Heritage, 2013, str. 2), što ukazuje na porast svesti o značaju kulturne interakcije koja podstiče dijalog, gradi razumevanje i unapređuje toleranciju. Rast kulturnog turizma ogleda se i kroz finansijske pokazatelje. 
Procenjuje se da ovi turisti troše jednu trećinu više od prosečne turističke potrošnje (Richards, 2011, str. 21), tako da se kulturni turizam svrstava u deset najvažnijih i najdinamičnijih turističkih grana (UNWTO, 2001, str. 71), a sve veća ponuda kulturnih aktivnosti utiče na povećanje njegove konkurentnosti (Roland \& Buck, 2010, str. 185). Takav, rastući trend zainteresovanosti za kulturni turizam pruža priliku da kulturno nasleđe kao resurs razvoja postane održivo, donoseći koristi lokalnoj i široj zajednici uz preduslov njegovog očuvanja.

Najrazvijenije države sveta promovišu svoje kulturno nasleđe u svrhe turizma i ulažu veliki napor za njeno razumevanje i promociju, dok zemlje u tranziciji (poput Srbije), to nedovoljno čine, iako poseduju veliki potencijal kao zemlje kulturnog turizma (Nuryanti, 1996, str. 250). Srbija tu slabost može preokrenuti u prednost, jer veliki potencijali u nedovoljno eksponiranom nematerijalnom kulturnom nasleđu svojim obimom i kvalitetom mogu povećati turističku konkurentnost, a time doprineti podizanju svesti lokalnih zajednica i pomoći njegovom očuvanju. Za promenu je potrebno adekvatno prezentovanje i interpretacija nematerijalnog kulturnog nasleđa (Krasojević, 2013, str. 349). Rezultati projekta Podrška sprovođenju Nacionalne strategije razvoja turizma u Srbiji 2010-2012 ukazuju na potrebu da se u turističkoj ponudi Srbije akcenat stavi na istorijske kružne ture, priče, legende, mitove i njihovu interpretaciju na inovativan način, baziran na doživljaju i novim iskustvima, što predstavlja putokaz razvoja kulturnog turizma, ali i priliku koju sektor zaštite nematerijalnog kulturnog nasleđa ne sme da propusti (Evropska komisija 2010-2012).

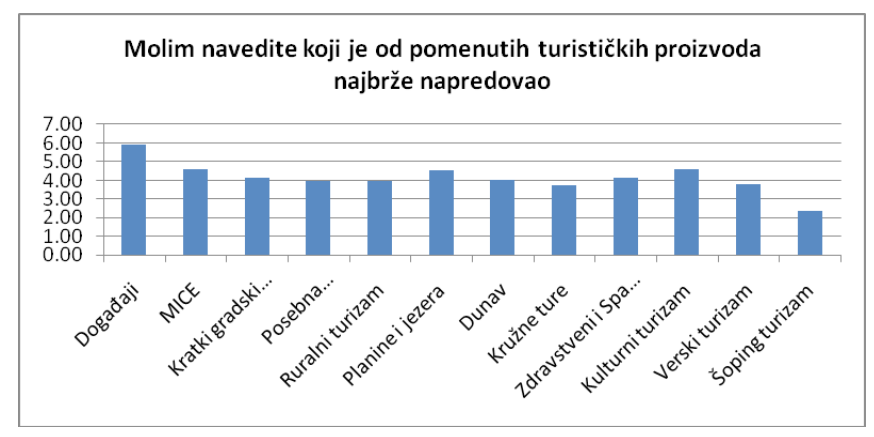

Sl. 1. Najbrže rastući turistički proizvodi u Srbiji

Rezultati anketiranja ključnih nosilaca turističke ponude Srbije u okviru pomenutog Projekta ukazuju da su najbrže rastući turistički proizvodi (Događaji, Kulturni, Ruralni i Verski turizam) upravo oni koji u velikom obimu sadrže elemente nematerijalnog kulturnog nasleđa

\section{OD KULTURNIH RESURSA DO KULTURNO- TURISTIČKIH PROIZVODA}

Sva materijalna i nematerijalna, prirodna ili kulturna dobra, kao činioci ambijentalnih celina, predstavljaju turističke resurse i mogu se koristiti u turističke svrhe, proizvesti privredni učinak i doprineti ekonomskom razvoju određene destinacije. Kulturni resursi mogu postati turistički resursi samo planskim oblikovanjem, a kulturni proizvodi postaju nakon procesa prezentacije i interpretacije. Kulturno-turistička i ekonomska vrednost resursa ocenjuje se na osnovu stepena atraktivnosti, estetskog utiska, osobenosti, znamenitosti, ali i povoljnosti geografskog položaja, udaljenosti i saobraćajne povezanosti s emitivnim turističkim tržištima, veličinom izvora tražnje, položajem resursa u odnosu na glavne turističke tokove i konkurentske i komplementarne turističke prostore (Mc Kercher \& du Cros, 2002, str. 47). Kulturno-turistički proizvod je spoj atraktivnosti glavnog (kulturno-istorijski spomenici, manifestacije i usluge muzejskog, odnosno spomeničkog turističkog vođenja) i dodatnog proizvoda (lokacija, smeštaj, prevoz, opšte turističke usluge, ponude turističko-informativnih centara, saobraćajna infrastruktura) kao elemenata opšteg turističkog proizvoda (Sigala \& Leslie, 2005, str. 28-29).

Poslednjih godina fokus interesovanja i ponude kulturnog turizma se pomera od dominantne zastupljenosti nepokretnog, ka pokretnom, te nematerijalnom nasleđu i proizvodima kulturnih industrija. Ovakav pomak, pored svih pozitivnih strana, krije i određene opasnosti, prvenstveno vezane za nekontrolisanu eksploataciju ovih resursa. Iz tog razloga, upravljanje kulturnim nasleđem u celini podrazumeva sistemsku brigu, kako bi ono bilo dostupno, ne samo sadašnjim, već i budućim generacijama (Jelinčić, 2010, str. 26).

Ponuda turizma zasnovana na kulturnim resursima intenzivira međusobni uticaj kulture i turizma i umanjuje negativne efekte na lokalne zajednice. Dok promocija materijalnog kulturnog nasleđa ima dugu tradiciju, nematerijalno nasleđe tek počinje da zauzima svoje mesto u turističkoj ponudi (Stjuard, 1981, str. 9; Bandić, 1997, str. 240).

\section{NEMATERIJALNO KULTURNO NASLEĐE KAO RESURS RAZVOJA TURIZMA U SRBIJI}

Srbija je Uneskovu Konvenciju o očuvanju nematerijalnog kulturnog nasleđa ratifikovala 2010. godine. Međutim, ni do decembra 2014. nematerijalno kulturno nasleđe nije dobilo svoje mesto u pozitivnom zakonodavstvu Republike Srbije (Đorđević, 2012, str. 55-58). U takvoj situaciji, primenjuju se odredbe Konvencije, kao zakonskog akta starijeg od trenutno važećeg, a nepotpunog Zakona o kulturnim dobrima iz 1994. godine (Službeni glasnik RS 71/94). Ratifikacijom ove Konvencije, Srbija se obavezala da će preduzeti mere za obezbeđivanje očuvanja nematerijalnog kulturnog nasleđa na svojoj teritoriji i da će usvojiti odgovarajuće pravne, tehničke, administrativne i finansijske mere u cilju jačanja institucija za obuku u upravljanju nematerijalnim kulturnim nasleđem, uz garantovanje pristupa nematerijalnom kulturnom nasleđu (Konvencija o očuvanju nematerijalog kulturnog nasleđa, članovi 11-13). Garant ispunjavanja navedenih obaveza upravo je donošenje odgovarajućih zakona kojima bi se obezbedili pravni okviri očuvanja nematerijalnog kulturnog nasleđa u Srbiji. Tako bi rad stručnih tela i institucija koji se staraju o sprovođenju konvencije dobio na značaju, a nosioci elemenata nematerijalnog kulturnog nasleđa, upisanih i predloženih za Nacionalni registar, dobili potvrdu da će njihova prava i obaveze koja su tom nominacijom stekli biti sprovedena u praksi. Kako bi sistem zaštite nematerijalnog nasleđa u Srbiji bio adekvatno sprovođen formirana je mreža zaštite, koja se vremenom menjala (Đorđević, 2012, str. 56). Mrežu sačinjavaju Nacionalni komitet za nematerijalno kulturno nasleđe, Centar za proučavanje nematerijalnog kulturnog nasleđa pri Etnografskom muzeju, regionalni koordinatori i Komisija za upis na Listu nematerijalnog kulturnog nasleđa, takođe pri Etnografskom muzeju, sastavljena od stalnih članova iz ove ustanove i promenljivih članova u zavisnosti od predloženih elemenata za upis, od kojih su dva člana iz Nacionalnog komiteta.

Prvi upisi u Nacionalni registar sprovedeni su 2012. godine, kada je predloženo i prihvaćeno 27 elemenata sa cele teritorije Srbije: porodična slava, molitva (đurđevdanski obred), belmuž, običaj izlivanja i paljenja ratarskih sveća, izrada pirotskog kačkavalja, pirotsko ćilimarstvo, filigranski zanat (Krist Beriša, kujundžija iz Kraljeva), klesarski zanat (selo Bela Voda kod 
Kruševca), pazarske mantije, zlakuska lončarija, kosovski vez, pevanje uz gusle, groktalica, pevanje izvika, erski humor, kolo (kolo u tri, kolo u šest), kolo Rumenka, sviranje na gajdama i kavalu, frulaška praksa, naivno slikarstvo Slovaka, Lazarice u Sirinićkoj župi, izrada drvenih čutura u selu Pilica, Vukov sabor, ojkača, vranjska gradska pesma i Čuvanje Hristovog groba.

Od novembra 2014. godine, Srbija ima jedan upisan element na Reprezentativnoj listi nematerijalnog kulturnog nasleđa čovečanstva. Reč je o „porodičnoj slavi“ čija je nominacija u domaćoj javnosti naišla na veliko odobravanje i učinila čitavu oblast nematerijalnog kulturnog nasleđa mnogo vidljivijom. Unosom ključnih reči „Krsna slava na UNESCO listi“ na Google pretraživaču 21.02.2015. dobijeno je 7970 rezultata.

U Srbiji se prikupljaju i evidentiraju elementi nematerijalnog kulturnog nasleđa u širem obimu, kako bi se ono očuvalo, razvilo i adekvatno vrednovalo. Kulturne institucije i lokalne zajednice rade na prepoznavanju vrednosti kulturnog nasleđa, očuvanju, održanju i razvoju živog ljudskog nasleđa i poboljšanju društvenog i pravnog statusa nosilaca nematerijalnog kulturnog nasleđa i nasleđa uopšte. Međutim, i dalje nedostaju konkretnije promotivne akcije.

Analiza stanja pokazuje da je u turističkoj ponudi Srbije nematerijalno nasleđe zastupljeno u vrlo ograničenom obimu. Uloga lokalnih turističkih organizacija od suštinskog je značaja za njihovu promociju i povećanje vidljivosti, jer one „na svojoj teritoriji“ najbolje poznaju vrednosti za potrebe turizma. Iskustvo zemalja u kojima kulturni turizam ima dobro osmišljene programe pokazuje da turistička ponuda ne sme biti odvojena od potreba i senzibiliteta lokalnih zajednica. Programi pravljeni i za potrebe lokalne zajednice će privući turiste, dok će oni pravljeni za turiste, privući samo turiste čime se dovodi u pitanje njihova opravdanost i održivost (Ripkema, 2014).

\section{NEMATERIJALNO KULTURNO NASLEĐE U TURISTIČKOJ PONUDI SRBIJE}

Nematerijalno kulturno nasleđe u Srbiji je sve češće predmet interesovanja javnosti, a lokalne zajednice sve više imaju potrebu da osete i materijalnu korist njegove eksploatacije u turističke svrhe. Koliko u tome uspevaju, može se sagledati kroz nekoliko primera.

Molitva kao komercijalna manifestacija, koja dvadesetak godina prati tradicionalni đurđevdanski obred, u podnožju Stare Planine kod Knjaževca, 2014. godine je dobila nagradu za najbolju turističku destinaciju u okviru konkursa EDEN Turističke organizacije Srbije na temu „Turizam i lokalno nematerijalno kulturno nasleđe“.

Običaji i tradicija manjinskih naroda (Roma, Slovaka, Vlaha, Mađara, Rusina, Šokaca, Bunjevaca, Albanaca, Bošnjaka i ostalih) čini dodatnu vrednost turističke ponude Srbije jer je „nematerijalno kulturno nasleđe tekovina savremenih i dinamičkih procesa i kao takvo se zaštićuje i vrednuje, postajući ekskluzivno dobro različitih kultura" (Lukić Krstanović \& Divac, 2012, str. 12). Upis naivnog slikarstva Slovaka (Blagojević, 2012, str. 185-195) u Registar nematerijalnog kulturnog nasleđa Srbije važna je komponenta turističke ponude opštine Kovačica. Kroz moto „Cela varoš slikarski atelje“ lokalna zajednica, predvođena Pavelom Babkom, vlasnikom Galerije Babka, sistemski i permanentno promoviše naivno slikarstvo Slovaka i održava interesovanje domaće, ali i svetske javnosti. Naivno slikarstvo Slovaka bilo je deo predstavljanja kulturnih vrednosti Srbije na izložbi EXPO 2010. u Šangaju.

Vukov Sabor koju organizuje Centar za kulturu „Vuk Karadžić“ iz Loznice, najstarija je kulturna manifestacija u Srbiji.
Misija Vukovog sabora - negovanje srpskog jezika i književnosti, dobija na aktuelnosti, pa je formiran Muzej jezika u kome se prikupljaju toponimi i ukazuje na značaj priče i prepričavanja, sa idejom da predmet podrži priču, a ne obrnuto. Sama manifestacija, dugim trajanjem i institucionalnom organizovanošću, obezbedila je održivost i time se potvrdila kao primer dobre prakse.

Na lokalnim saborima i festivalima u Zapadnoj Srbiji promovišu se elementi nematerijalnog nasleđa pevanje izvika i erski humor (Nikolić, 1997, str. 149-159). Erski humor se, zahvaljujući velikom zalaganju Biblioteke „Ljubiša Đenić“ iz Čajetine, održava, promoviše i predstavlja kroz letnji turistički program na Zlatiboru.

Zlakuska lončarija, koja je među najpoznatijima sa Liste nematerijalnog kulturnog nasleđa Srbije, poslednjih decenija beleži konstantni porast interesovanja javnosti, ali i pokazuje da sama svest lokalne zajednice o značaju nasleđa koje baštini nije dovoljna. Od devedesetih godina prošlog veka, kada je ovaj specifičan način izrade posuda na ručnom vitlu bio u izumiranju, do danas, broj lončara višestruko je povećan (Đorđević, 2007, str. 87-99). Veća tražnja njihovih proizvoda i primetno veće interesovanje za samo selo, podstakla je celokupnu zajednicu da svoje potencijale učini održivim. Tako su nastali:

Etno park „Terzića avlija“, koji se bavi izlagačkom i turističkom delatnošću i organizacijom ekoloških programa;

Etno udruženje „Zavičaj“, koje okuplja folklorne izvođačke grupe i organizuje manifestacije „Zlakusa u pesmi i igri“ $i$ „Raspevana avlija“;

Udruženje lončara „Zlakusa“, koje radi na očuvanju autentičnog tehnološkog postupka, unapređenju kvaliteta i borbi protiv falsifikovanja zlakuskih proizvoda registrivanjem žiga i apliciranjem za oznaku geografskog porekla kod Zavoda za intelektualnu svojinu (Đorđević, 2007:87-99);

Udruženje žena „Zlakušanke“, koje okuplja meštanke vične spremanju tradicionalnih jela, itd. Manifestacija koja bi trebalo da promoviše zlakusko lončarstvo - Lončarijada, u okviru šire manifestacije „Jesen u Zlakusi“ u kojoj učestvuju sva pomenuta udruženja. Iako, prvobitno dobro zamišljena, nije uspela da se izbori sa zahtevima šire zajednice, pa je ručno vitlo i žižanicu (Tomić, 1983, str. 24-33; Đorđević, 2011, str. 32-55), zamenila preglasna muzika pod šatrama.

Zlakuski lonci su danas na manifestaciji pod imenom „Demonstracija gradnje lonaca i pečenja na otvorenoj vatri“ minorno zastupljeni, dok su prvih godina bili najvažniji deo programa. $\mathrm{Na}$ ovom primeru se vidi kako nekontrolisana eksploatacija kulturnih resursa može da dovede do pojava koje mogu da ugroze i samo kulturno dobro. Rizici i štete se mogu izbeći ukoliko lokalna zajednica sarađuje sa institucijama zaštite kulturnog nasleđa i lokalnim turističkim organizacijama. Sinergija ova tri subjekta obezbeđuje održivost elemenata, što je ključ strategije razvoja i zaštite nematerijalnog kulturnog nasleđa i kulturnog turizma koju bi trebalo slediti.

\section{KULTURNI FAKTORI U REVIZIJI STRATEGIJE RAZVOJA TURIZMA SRBIJE}

Projekat „Podrška sprovođenju Nacionalne strategije razvoja turizma u Srbiji” (2010-2012) koji je finansijski podržala Evropska unija imao je za cilj da podstakne veći doprinos turizma u srpskoj ekonomiji, u skladu sa najboljom praksom u EU (Krasojević, 2013, str. 218-222). S tim u vezi, istraživanje za potrebe revizije Strategije razvoja turizma sprovela je Agencija za istraživanje tržišta i javnog mnjenja „MASMI“ iz Beograda, u sastavu istraživačke mreže „MASMI Research Group“ sa se- 
dištem u Londonu. Uzorak je obuhvatio 1.500 turista i to: U Beogradu 20\%, Zapadnoj Srbiji (Zlatibor) 13\% i Kopaoniku $12 \%$, a najmanje u Donjem Podunavlju (2\%) i Novom Pazaru (1\%). Rezultati istraživanja ukazuju na moguće pravce razvoja turizma Srbije. Svaki treći turista poseti Srbiju više puta godišnje $31,8 \%$, svake godine Srbiju poseti 35,3\% turista, a 15\% turista svake druge godine. Srbija svake godine privuče 7,5\% „novih“ turista. Glavni motivi dolaska turista su zadovoljstvo $(37,1 \%)$, provod i zabava (20,7\%). Rezultati istraživanja o odlučujućim faktorima za izbor destinacije potvrđuju da se pri donošenju odluke o putovanju u Srbiju turisti rukovode raznovrsnošću i kvalitetom ponude $(27,8 \%)$, izborom lokalne hrane i pića $(21,1 \%)$ i cenama (18,7\%). Skoro 32\% putnika motivisano je dobrim prethodnim iskustvima. Svakog četvrtog turistu privlači dobra atmosfera i ukupan izgled.

Na slici broj 2 uočava se da u kulturnoj ponudi, događaji i zabava najviše utiču na opredeljenje za posetu Srbiji $(42,4 \%)$, dok su kulturni i umetnički programi zastupljeni sa 15,9\%, a gradski pejzaži, izgled i arhitektura sa $13,4 \%$.

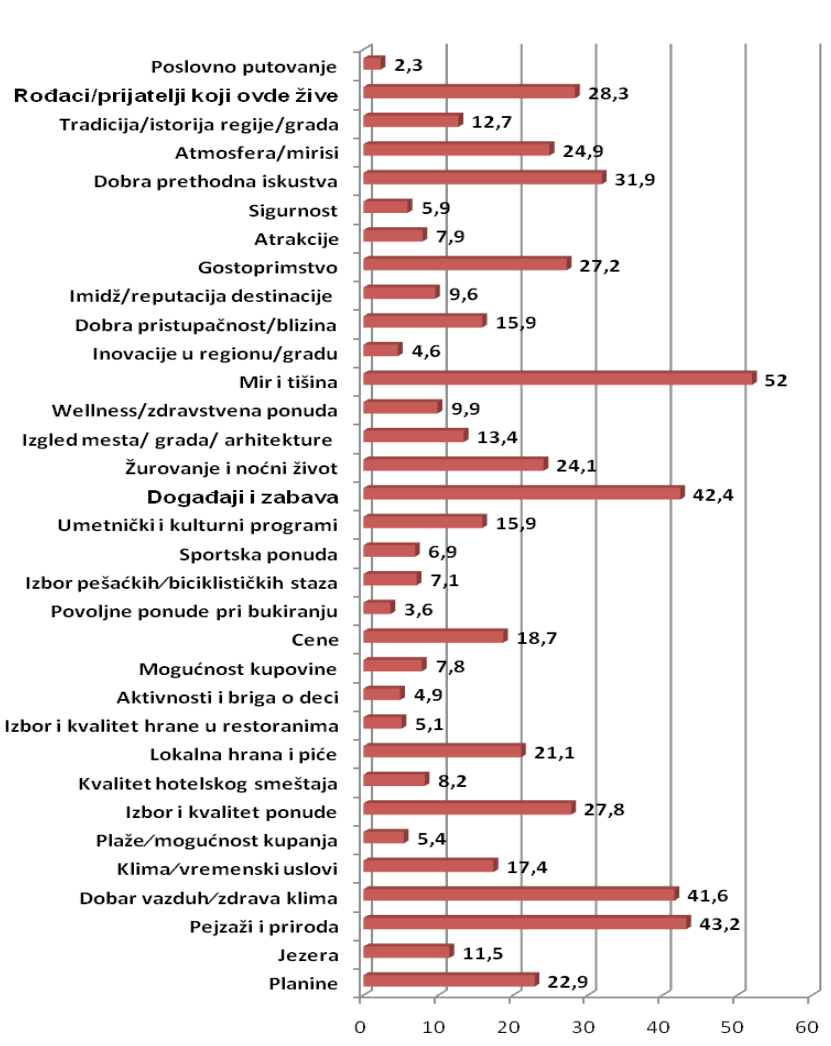

Slika 2. Odlučujući faktori za izbor turističke destinacije ispitanika (u \%)

Izvor: Istraživanje agencije MASMI (2011)

Ovi podaci ukazuju na činjenicu da je nematerijalna kultura ostala neprepoznata i nedovoljno jasno prezentovana turistima, mada je de facto inkorporirana u napred pomenute elemente. Nameće se utisak da je nužna stalna analiza i istraživanje tržišta u kulturi i turizmu, naročito na lokalnom nivou. Projekti unutar kulturnog turizma zahtevaju selekciju kulturnih resursa, idejnu koncepciju uz prateću interpretaciju, razradu i finansijsku konstrukciju, implementaciju, promociju, monitoring kulturne atrakcije i evaluaciju (Jelinčić, 2006, str. 161-183).

Revizija Strategije razvoja turizma Srbije ukazala je na moguće strateške pravce daljeg razvoja turizma na nacionalnom planu. Prema rezultatima ovog projekta (Krasojević, 2011, str. 66-67), šanse Srbije da iskoristi svoje kulturne potencijale rastu, posebno na novim turističkim tržištima i kod turista u „zrelijim godinama”. Potvrđeno je da je kultura snažan motiv za dolazak turista u Srbiju, posebno onih koji to čine po prvi put. Predlaže se da se u kulturno-turističkoj ponudi akcenat stavi na istorijske kružne ture, mitove i interpretaciju zanimljivih pojava i događaja na inovativan način, baziran na doživljaju i novom iskustvu. Lokalna kultura, način života i tradicija, naročito u Evropi, značajan je faktor privlačnosti, posebno za turiste sa nižim platežnim mogućnostima, zainteresovanim za nova turistička tržišta sa umerenijim cenama, poput Srbije. Ovo ukazuje na proširenje tržišta na kojima se turistička ponuda bazirana na kulturnim resursima, može uspešno plasirati. Zaključuje se da se pri planiranju razvoja kulturno-turističkog proizvoda moraju uključiti sve zainteresovane strane - državne institucije, lokalne vlasti, predstavnici turističke privrede i kulturnih institucija, regionalnih i lokalnih turističkih organizacija, Srpske pravoslavne crkve, regionalnih razvojnih agencija, turističkih vodiča i svi drugi koji imaju koristi od razvoja kulturnog proizvoda, a čiji su stavovi i mišljenja od značaja za proces planiranja i odlučivanja.

\section{REZIME}

Nematerijalno kulturno nasleđe u turističkoj ponudi Srbije je nedovoljno zastupljeno i turistički vrednovano. Uglavnom čini samo deo sadržaja turističkih manifestacija, nema adekvatnu distribuciju i često se obezvređuje neodgovarajućom prezentacijom i prodajom. Međutim, nematerijalna kultura bi mogla postati maxime armata ukoliko bi se više uključila u turističke programe turoperatora i turističkih organizacija. Pri tom je integralni pristup kao mozaik materijalnih i nematerijalnih kulturnih i prirodnih resursa povezanih u jedinstven turistički proizvod najpreporučljiviji.

Suština kulturnog nematerijalnog proizvoda u turizmu je njegova interpretacija koja treba da omogući turistima doživljaj kulture u prošlosti i sadašnjosti. U tom smislu, neophodno je izgraditi partnerske odnose i pokrenuti zajedničke projekte sa svim zainteresovanim stranama uz istovremeno očuvanje nematerijalnog kulturnog nasleđa. Potrebno je napravi pregled i uskladiti zakone, pravila i propise koji regulišu nematerijalnu kulturnu baštinu od značaja za turizam Srbije kako bi se obezbedilo kvalitetno prezentovanje i interpretacija od strane turističkih vodiča, sprečila nezakonita prodaja i zaštitila prava intelektualne svojine u vezi sa izradom suvenira i drugih predmeta na bazi nematerijalnog nasleđa (tradicionalna muzika, kulinarski recepti, kozmetika, medicinski preparati). Lokalne samouprave u saradnji sa turističkim organizacijama bi trebalo da prepoznaju, zaštite i adekvatno prezentuju svoj kulturno-istorijski identitet i kroz nematerijalne elemente kulturnog nasleđa. Prilika za to su brojne manifestacije, proslave, vašari, stari i umetnički zanati, običaji, svetkovine, narodna verovanja, specijalizovani mali muzeji (poput muzeja hleba u Pećincima ili muzeja meda i vina u Sremskim Karlovcima), narodna izvorna muzika, folklor, priprema i degustacija lokalnih gastronomskih specijaliteta, itd.

U cilju povećanja konkurentnosti kulturno-turističkih proizvoda Srbije potrebno je otkriti i razumeti motive turističke tražnje i potrebe i mogućnosti turističke destinacije, odnosno lokalne zajednice. Turističkom ponudom se mora aktivirati proces stvaranja kulturnih znanja preko oživljene, a ne „uspavane“ kulturne baštine. Strategija razvoja turizma Srbije (20062015.) ponudila je matricu atraktivnosti i konkurentnosti turističkih proizvoda, a njena revizija (2010-2012.) je kroz projekat „Podrška sprovođenju Nacionalne strategije razvoja turizma u Srbiji” potvrdila da veliki kulturni potencijali zemlje mogu doprineti socio-ekonomskom razvoju, generisanju prihoda, jačanju deviznih rezervi i otvaranju novih radnih mesta. Uprkos 
ovoj verifikaciji Srbija nije izgradila konkurentu kulturno-turističku ponudu baziranu na materijalnom, a naročito na nematerijalnom kulturnom nasleđu. $U$ ponudu bi trebalo uključiti i organizovanu prodaju proizvoda na bazi nematerijalnog nasleđa preko medija i ovlašćenih prodavaca (suvenirnica, muzeja, aerodroma, hotela, turističkih agencija i tuističkih organizacija).

\section{LITERATURA}

Bandić, D. (1997). Carstvo zemaljsko, carstvo nebesko. Beograd: BIGZ.

Blagojević, G. (2012). Naivno slikarstvo kao priča o etnokulturnom identitetu Slovaka u Srbiji: primer Kovačice, Zbornik Matice srpske za društvene nauke, br.139/2:185-195.

Blanke, J., \& Chiesa, T. (2013). Travel Tourism Competitiveness Report. Preuzeto 20. Decembra 2014. sa http://www. weforum.org/reports/travel-tourism-competitiveness-report-2013 18

Brent, R., \& Geoffrey, I.C. (2003). The Competitive Destination: A sustainable tourism perspective. Wallingford UK: CABI Publishing.

Conrady, R., \& Buck, M. (2010). Trends and Issues in Global Tourism 2010. Berlin: Springer, ITB.

Đorđević, B. (2007). Etnoarheološka istraživanja kao vid zaštite tradicionalnih tehnologija keramike, u: M. Popović-Živančević (Ed). Condition of the Cultural and Natural Heritage in the Balkan Region, Vol. 1, Proceedings of the Regional Conference held in Kladovo October 2006. Belgrade: Narodni muzej.

Đorđević, B. (2011). Tri lica tradicionalne keramičke produkcije u Srbiji/Three facets of traditional pottery making in Serbia. Beograd: Narodni muzej.

Đorđević, B. (2012). Nematerijalno kulturno nasleđe - analiza pravnog okvira na primeru tradicionalne keramičke proizvodnje, Muzeološke sveske 15. Beograd: Narodni muzej.

Đorđević, B. (2014). Ekomuzeji i kreativni turizam: neiskorišćen potencijal Srbije. Muzeji i kulturni turizam, Zlatibor, 8-10.09.2014. Knjiga apstrakta, str. 44.

European Commission. (2007). Podrška sprovođenju Nacionalne strategije razvoja turizma u Srbiji 2011/2012. Preuzeto 20. Decembra 2014. sa http://ec.europa.eu/enlargement/pdf/ serbia/ipa/support_to_implementation_of_tourism_strategy_en.pdf

Grabler, K., Sirše J., \& Downes, J.J. (2011). Support to implementation of the National Strategy for Tourism: Review with proposals for competitive update Final draft. Belgrade: $\mathrm{Hu}-$ man Dynamics.

Human Dynamics. (2012). Rezultati projekta Podrška sprovođenju Nacionalne strategije razvoja turizma u Srbiji 2010-2012. Preuzeto 21. Decembra 2014. sa http://www. humandynamics.org/reference/support-implementationnational-strategy-tourism

Jelinčić, D.A. (2010). Kultura u izlogu. Zagreb: Intermedia.

Krasojević, B. (2013). Strateško upravljanje kulturnim resursima u turizmu Srbije, Doktorska disertacija. Beograd: Univerzitet Singidunum.

Lukić Krstanović, M. Divac, Z. (2012). Programiranje nematerijalnog kulturnog nasleđa grada. Glasnik etnografskog instituta SANU, LX (2), 21.

McKercher, B. du Cros, H. (2002). Cultural tourism - The Partnership Between Tourism and Cultural Heritage Management. New York: The Haworth Hospitality Press.
Ministarstvo kulture i informisanja. (2003). Konvencija o očuvanju nematerijalnog kulturnog nasleđa, članovi 11-13. Preuzeto 21. Decembra 2014. sa http://www.kultura.gov.rs/ docs/stranice/82128418889499865927/11.\%20Konvencija\%20o\%20ocuvanju\%20nematerijalnog\%20kulturnog\%20 nasledja\%20\%28Pariz\%202003\%29.pdf

Ministarstvo kulture i informisanja. (2014). Porodična slava kao predlog za upis na Unesko listu. Preuzeto 21. Decembra 2014. sa http://nkns.rs/2014/11/slava-na-uneskovoj-reprezentativnoj-listi-nematerijalnog-kulturnog-nasledja-covecanstva/ Jelinčić, D.A. (2006) Turizam vs Identitet-Globalizacija i tradicija, Etnološka istraživanja. Zagreb: Institut za međunarodne odnose, str. 161-183.

Nikolić, D. (1997) Anegdota - izraz erskog mentaliteta, Glasnik Etnografskog instituta SANU. XLVI, 149-159.

Nuryanti W. (1996). Heritage and Postmodern Tourism, Annals of Tourism Research, 23, 250.

OECD. (2001). Glossary of Statistical terms. Preuzeto 20. Decembra 2014. sa http://stats.oecd.org/glossary/detail. asp?ID=399

Popović-Živančević, M. (2012). Integrativna zaštita baštine sa metodologijom preventivne konzervacije. Beograd: Centralni institut za konzervaciju.

Richards, G. (2011). Cultural tourism trends in Europe: a context for the development of Cultural Routes. In: KhovanovaRubicondo, K. (Ed.) Impact of European Cultural Routes on SMEs' innovation and competitiveness.Strasbourg: Council of Europe Publishing.

Ripkema, D. (2014). Nasleđe i kreativna ekonomija. Drugi forum kreativne ekonomije, u organizaciji Grupe za kreativnu ekonomiju, Palata Srbija, 7. novembar 2014.

Sigala, M., \& Leslie, D. (2005). International Cultural Tourism: Management, implications and cases.Oxford: Elsevier Butterworth-Heinemann.

Stjuard, Dž.(1981). Teorija kulturne promene. Beograd: BIGZ.

Timothy, J. D. (2011). Cultural Heritage and Tourism:An Introduction. Bristol: Channel View Publications.

Tomić, P. (1983). Grnčarstvo u Srbiji. Beograd: Etnografski muzej.

UNESCO. (2013). Intangible cultural heritage: A force for Sustainable development Preuzeto 20. Decembra 2014. sa http:// www.unesco.org/new/en/media-services/in-focus-articles/ intangible-cultural-heritage-for-sustainable-development/

UNWTO. (2001). Tourism 2020 Vision - World Tourism Organization. Global forecast, 7, 71.

UNWTO. (2013). Study on Tourism and Intangible Cultural Heritage, Madrid, 2013. Preuzeto 20. Decembra 2014. sa http://dtxtq4w60xqpw.cloudfront.net/sites/all/files/pdf/ a20_10_activities_wcte_election_members_new_wcte_ part_i_en.pdf

UNESCO. (2003). Text of the Convention for the Safeguarding of the Intangible Cultural Heritage. Preuzeto 13. Decembra 2014. sa http://www.unesco.org/culture/ich/index. php?lg=en\&pg=00006

UNESCO. (2003). The States Parties to the Convention for the Safeguarding of the Intangible Cultural Heritage (2003). Preuzeto 13. Decembra 2014. Sa http://www.unesco.org/ culture/ich/index.php?lg=en\&pg=00024 